\title{
Parental Expectation from Children with Cochlear Implants in Indian Context: a Questionnaire Based Study
}

\author{
Prawin Kumar $^{1}$ Himanshu Kumar Sanju ${ }^{1} \quad$ Rajkishor Mishra ${ }^{2} \quad$ Varun Singh $^{1} \quad$ Priyanka Mohan ${ }^{1}$ \\ ${ }^{1}$ Department of Audiology, All India Institute of Speech and Hearing, \\ Mysore, Karnataka, India \\ 2 Department of Audiology, Bloom Senso Hearing Centre, \\ Kolkata, West Bengal, India \\ Address for correspondence Himanshu Kumar Sanju, C/O Dr. Prawin \\ Kumar, PhD, Department of Audiology, All India Institute of Speech \\ and Hearing, Mysore 570006, Karnataka, India \\ (e-mail: himanshusanjuaiish@gmail.com).
}

Int Arch Otorhinolaryngol 2017;21:156-160.

\begin{abstract}
Introduction Parental support is important in the habilitation/rehabilitation of children using cochlear implant devices. Hence, it is important for families to know the realistic expectations regarding outcomes from Cls.

Objective The objective of the present study is to know the parents' expectation from children using $\mathrm{Cls}$.

Methods For this study, we recruited 23 parents of children using Cls. We administered 15 questions translated in to Hindi related to communication abilities, social skills, academic achievement, change in future life, rehabilitation demand, and stress due to hearing impairment.

Results The response of the questions (5-point rating scale) related to communication abilities showed that parents were expecting children using $\mathrm{Cls}$ to use the telephone (95\%), to be able to detect soft sounds (99\%), to listen in crowds $(86 \%)$, to be able to easily understand others (76\%), and to show improvement in communication skills (78\%). Similarly, for questions related to social skills showed $90 \%$ of the parents expecting that their children with Cls should be able to easily make friends with normal hearing peers, and $80 \%$ of the parents were expecting the children to achieve high standards in their reading and writing skills. Questions related to change in future life showed $86 \%$ of the parents expecting their children with Cls to act like normal hearing children. Further, $78 \%$ parents showed positive response regarding importance of

Keywords

- cochlear implants

- parents

- questionnaires intensive training. However, $70 \%$ of the parents reported stress in the family due to the existence of the hearing impaired child.

Conclusion Overall, the existing questionnaire-based study showed that parents have high expectations from their children with cochlear implant.
\end{abstract}

\section{Introduction}

Cochlear implant is the most advanced and successful neural prosthesis developed to date. The number of cochlear implant recipients outnumbers the recipients of all other types of neural prostheses by orders of magnitude, and it is the most effective prosthesis in terms of restoration of function. Cochlear implants can provide hearing in patients with damage to the sensory hair cells in their cochlea. However the effectiveness of the implant and intervention depends on many factors, such as the child's general developmental potential, age at which implant was done, and anatomy and received

December 20, 2015

accepted

April 12, 2016

published online

May 30, 2016
DOI http://dx.doi.org/

10.1055/s-0036-1584228. ISSN 1809-9777.
Copyright (c) 2017 by Thieme-Revinter

Publicações Ltda, Rio de Janeiro, Brazil
License terms

(c) (1) $\odot \circledast$ 
physiology of the inner ear and auditory pathway. Family and parents play an important role in the child's development in acquiring auditory experience and spoken language. In healthcare, more attention is paid to structured behavioral outcome than to the collection of information of everyday functional level. In pediatric cochlear implantation, the support of parents and family members is very important in the habilitation/rehabilitation of children. Studies have emphasized that goals and wishes of parents should be taken seriously during planning of implantation and habilitation and in setting joint goals of intervention. ${ }^{1}$ Few stakeholders have extensively researched about cochlear implants (CI), while others arrive at the decision-making process with limited information about the technology and its outcomes. Hence, it is important for families to know the realistic expectations regarding outcomes from Cls.

Interviews and open or closed format or semi-structured questionnaires are specifically constructed for pre-implant and follow-up intervention and are more informative than any other instrument. A questionnaire on parental expectations from children with cochlear implant will provide information on real life situations. There are very few studies which explore parental expectations ${ }^{2-4}$ satisfaction with implant habilitation, ${ }^{5}$ parental stress, ${ }^{6}$ the quality of life of implanted children and that of their families, ${ }^{7}$ using interviews and parental questionnaires. Due to the diversity in the cultural differences and socioeconomic status in the Indian context, it is very important to study the change in the quality of life based on parental expectation before and after the implantation. The parental view will provide information to the health care professionals on what is important to families and what variations can help toward better intervention and rehabilitation of the children with Cls. The main domains in which parents expect improvement from the cochlear implant for the child include communication abilities, social skills, and academic achievements, as well as a change in their future life, rehabilitation demand, parental satisfaction and a stress-free life. With this in mind, this study aims to understand parents' expectations from children using CIs in the above-mentioned domains in the Indian context.

\section{Method}

We recruited children in the age range of 3 to 8 years old (mean age of 5.5 years) using cochlear implant from 2 to 6 years old for the study. We administered a questionnaire composed of 15 questions related to communication abilities ( 5 questions), social skills ( 2 questions), academic achievement ( 2 questions), change in future life (2 questions), rehabilitation demand (2 questions), and stress due to hearing impairment (2 questions) on the parents of all the children. Questions were selected from a list prepared by Nemours Clinic, Florida, USA. We translated these questionnaires into Hindi and performed the reverse translation to make sure that the meaning of the content remains the same. Then, a native speaker of Hindi with knowledge of English as well proofread these translated questions in Hindi. Later, we used the same questionnaire for the participants under close supervision of audiologists. These questions were closed-set tasks with a 5-point rating scale. We randomly selected all the parents of $\mathrm{Cl}$ children based on their willingness to participate in the study. They received a detailed explanation about the purpose of the study. They belonged to low-to-medium socio-economic status and were educated up to graduation. Primarily, the mother tongue of all the participants was Hindi with a little knowledge of English. We took oral informed consent from all participants. The ethical committee of the All India Institute of Speech and Hearing, Mysuru-6, Karnataka, India, approved the study. We analyzed the data using SPSS (version 17), along with descriptive statistics, percentages, and proportions of the study subjects, within the context of a particular response.

\section{Results}

We described the percentages and proportions of different categories of questionnaires under different headings as a table and graphical representation.

\section{Communication Abilities}

- Table 1 shows the response of the parents on questions related to communication abilities. The table indicates a high expectation of parents in terms of communication abilities from their children.

\section{Social Skills}

-Table 2 shows the responses to the questions related to social skills.

\section{Academic Achievement}

- Table 3 shows the responses to the question related to academic achievement.

Table 1 Responses obtained for the question asked about expectation of improvement in communication abilities

\begin{tabular}{|c|c|c|c|c|c|}
\hline & $\begin{array}{l}\text { Strongly } \\
\text { disagree }\end{array}$ & Disagree & Neutral & Agree & $\begin{array}{l}\text { Strongly } \\
\text { agree }\end{array}$ \\
\hline Will be able to use telephone & $0 \%$ & $0 \%$ & $4.30 \%$ & $43.4 \%$ & $52.1 \%$ \\
\hline Will be able to easily detect very quiet sounds & $0 \%$ & $0 \%$ & $0 \%$ & $52.1 \%$ & $47.8 \%$ \\
\hline Will be able to follow a conversation with group of peoples & $0 \%$ & $8.6 \%$ & $4.3 \%$ & $60.86 \%$ & $26.08 \%$ \\
\hline Will improve his/her communication skill tremendously & $0 \%$ & $0 \%$ & $21.73 \%$ & $52.1 \%$ & $26 \%$ \\
\hline $\begin{array}{l}\text { Will be able to easily understand others without having } \\
\text { them repeat themselves }\end{array}$ & $0 \%$ & $0 \%$ & $8.6 \%$ & $47.8 \%$ & $43.4 \%$ \\
\hline
\end{tabular}


Table 2 Responses obtained for the question asked about expectation of improvement in social skills

\begin{tabular}{|l|l|l|l|l|l|}
\hline & Strongly disagree & Disagree & Neutral & Agree & Strongly agree \\
\hline Will easily make friends with hearing peers & $0 \%$ & $8.7 \%$ & $0 \%$ & $56.52 \%$ & $34.7 \%$ \\
\hline Will be accepted by his classroom hearing peers & $0 \%$ & $0 \%$ & $21.7 \%$ & $21.7 \%$ & $56.5 \%$ \\
\hline
\end{tabular}

Table 3 Responses obtained for the question asked about expectation of improvement in academic performance

\begin{tabular}{|c|c|c|c|c|c|}
\hline & $\begin{array}{l}\text { Strongly } \\
\text { Disagree }\end{array}$ & Disagree & Neutral & Agree & $\begin{array}{l}\text { Strongly } \\
\text { Agree }\end{array}$ \\
\hline Will improve tremendously in his/her academic achievement & $0 \%$ & $13 \%$ & $8.6 \%$ & $39.1 \%$ & $39.1 \%$ \\
\hline Will be able to participate easily in regular classroom activities & $0 \%$ & $0 \%$ & $4.3 \%$ & $47.8 \%$ & $47.8 \%$ \\
\hline
\end{tabular}

\section{Change in Future Life}

- Table 4 shows the responses to the question on changes in future life.

\section{Rehabilitation Demand}

- Table 5 shows the responses to the question about rehabilitation demand.

\section{Stress due to Hearing Impairment}

- Table 6 shows the responses to the question asked about changes in future life.

\section{Discussion}

The present study showed parents' high expectations toward their children from using the cochlear implant.
The parents' response to questions asked about communication abilities revealed their high expectations regarding communication abilities. In fact, $95 \%$ of the parents agreed that their child would be able to use the telephone, $100 \%$ of the parents had an affirmative response to the question "Will be able to easily detect very quiet sounds." Similarly, on the question "Will be able to follow a conversation with group of peoples," $87 \%$ of parents agreed. The question asked about their opinion on "Will improve his/her communication skill tremendously," 78\% of the parents showed a positive response. Similarly, $90 \%$ of the parents gave a positive response on the question "Will able to easily understand others without having them repeat themselves." The results of the present study showed that parentś expectations are high toward CI children in the Indian context. The current study also indicated that $90 \%$ of the parents expect their

Table 4 Responses obtained for the question asked about expectation of changes change in future life

\begin{tabular}{|l|l|l|l|l|l|}
\hline & Strongly disagree & Disagree & Neutral & Agree & Strongly agree \\
\hline Will be able to function like a child with typical hearing & $0 \%$ & $0 \%$ & $13.04 \%$ & $56.5 \%$ & $30.04 \%$ \\
\hline Will have a dramatic change in his/her life & $0 \%$ & $0 \%$ & $13 \%$ & $56.52 \%$ & $30.04 \%$ \\
\hline
\end{tabular}

Table 5 Responses obtained for the question asked about knowledge of rehabilitation demand among parents

\begin{tabular}{|c|c|c|c|c|c|}
\hline & $\begin{array}{l}\text { Strongly } \\
\text { disagree }\end{array}$ & Disagree & Neutral & Agree & $\begin{array}{l}\text { Strongly } \\
\text { agree }\end{array}$ \\
\hline Will need to participate in intensive listening training & $0 \%$ & $8.6 \%$ & $13 \%$ & $13 \%$ & $65.2 \%$ \\
\hline $\begin{array}{l}\text { Parents of children with cochlear implants will have to } \\
\text { put in a lot of effort into the rehabilitation process }\end{array}$ & $0 \%$ & $17.3 \%$ & $13 \%$ & $8.6 \%$ & $60.8 \%$ \\
\hline
\end{tabular}

Table 6 Responses obtained for the question asked about stress related to hearing impairment

\begin{tabular}{|c|c|c|c|c|c|}
\hline & $\begin{array}{l}\text { Strongly } \\
\text { disagree }\end{array}$ & Disagree & Neutral & Agree & $\begin{array}{c}\text { Strongly } \\
\text { agree }\end{array}$ \\
\hline Stress in family is related to deafness / hearing impairment & $8.6 \%$ & $21.7 \%$ & $0 \%$ & $30.4 \%$ & $39.1 \%$ \\
\hline Child usually treated like normal hearing child by family and friends & $0 \%$ & $4.3 \%$ & $4.3 \%$ & $26.8 \%$ & $65.2 \%$ \\
\hline
\end{tabular}


child to easily make friends with hearing peers, whereas $76 \%$ of the parents gave positive response to the question "Will be accepted by his classroom hearing peers." The question related to academic achievement showed that $80 \%$ of the parents expected the children to achieve high standards in their reading and writing skills, which enforces their high expectation toward their children using $\mathrm{CI}$. Similarly, questions related to change in future life showed $86 \%$ of parents expecting their children with CIs to act like normal hearing children and that there should be a dramatic change in his/her life. Furthermore, $78 \%$ of parents showed a positive response regarding the importance of intensive training, which indicates awareness about importance of speech-language and listening training among parents. However, 70\% of the parents reported stress in the family due to existence of the hearing impaired child.

Stefanini et $\mathrm{al}^{8}$ administered a questionnaire on 50 parents or guardians of children using $\mathrm{CI}$, with minimum 1 year and maximum of 3 years of device use, and also demonstrated that parents have high expectations regarding communication, independence, and social participation of children after CI surgery. A similar study done by Nikolopoulos et $\mathrm{al}^{2}$ also reported the ability of cochlear implantation to meet or surpass parental expectations in three important outcome domains: communication, listening to speech, and the development of speech and language. Sach and Whynes ${ }^{9}$ conducted face-to-face semi-structured interviews with 216 families of children using cochlear implant. They reported that outcomes are highly individualistic, although parents had a shared hope of the implant enabling the child to function in a "hearing world."

In the present study, we also observed that $70 \%$ of the parents reported stress due to the existence of a hearing impaired child. Weisel et al ${ }^{10}$ investigated stress, attitudes, and expectations among mothers of deaf children who underwent cochlear implantation. They reported no differences emerged in stress levels with different groups of subjects, that is, mothers of $\mathrm{CI}$ candidates, $0-3$ years post-implantation, and more than three years later. They also reported that high levels of the mother's and father's education correlated with lower stress levels.

According to the outcomes of the present study, expectations from parents of $\mathrm{CI}$ children may be achieved as reported by Piazza et al, ${ }^{11}$ who showed that parents were satisfied by the performance of their children using cochlear implant. Speech language pathologist and audiologist should be aware of the high expectations of parents in terms of communication abilities of children using cochlear implant. The result of the present study can be used to identify specific areas of communication skills where professionals can work more intensively to meet the demand of parent's expectations. The result of present study also revealed the expectation of parents regarding improvement in social skills in children using cochlear implant. The professional should also focus on the improvement of social skills among children using cochlear implant to meet the parental demand. High demands related to academic achievement toward children using cochlear implant can be assured if professionals, such as special educators, help the children in an effective way and devise a method toward their achieving success in academics.

The questions related to awareness among parents regarding the importance of intensive rehabilitation therapy by the audiologist and the speech language pathologist showed most of the parents were aware of the importance of rehabilitation therapy (speech, language, and listening). This will help the clinician to give parents a better understanding of home training. However, the present study showed that $17 \%$ of parents were unware of the importance of rehabilitation therapy. Specialists should counsel parents regarding the benefits of intensive speech language therapy and listening training. They must ensure that parents of the children using cochlear implant are informed of the benefits of intensive speech language therapy and listening training.

Questions related to stress in the family of the children using CI showed anxiety among parents of children using CI. Realistic counseling by specialists should be effective in reducing stress among parents of children using CI. Quitter et $\mathrm{al}^{12}$ reported that parents of children with cochlear implants have a high degree of stress and poorer psychological adjustment when compared with parents of normal hearing children. Similarly, Sarant and Garrard ${ }^{13}$ investigated a stress questionnaire among parents of children using CI. They also reported that these parents had a higher incidence of stress than the normative population.

The current study also indicates that $90 \%$ of the parents expect that their children with CIs should be able to easily make friends with normal hearing peers. Kluwin and Stewart ${ }^{4}$ conducted an interview study of a random sample of 35 parents whose children had received cochlear implants through a large-scale implant program. Results showed that language and speech, rather than improved social skills or social contact, are the primary benefits of the implant. The outcome of present study showed that parents demand is high for improvement in communication abilities, social skills, and academic performance for their children using $\mathrm{CI}$. They were also aware of rehabilitation demand, that is, the importance of intensive speech, language, and listening training after surgery.

\section{Conclusion}

The current study showed the high expectation of parents toward their children using cochlear implants in terms of communication abilities, social skills, academic achievement, and change in their future life. The present study also showed awareness of intensive speech-language and listening training required for the children using cochlear implant. This study also indicates stress due to the existence of children with hearing impairment among parents. Based on the present study, it is reasonable to conclude that the rehabilitation professional must be aware of parental expectations toward their children that use the cochlear implant. Proper counseling on realistic expectations should be given at the different implantation stages: pre-implantation and postimplantation. 
160 Parental Expectation from Children with Cochlear Implants in India Kumar et al.

\section{References}

1 Zaidman-Zait A, Most T. Cochlear implants in children with hearing loss: maternal expectations and impact on the family. Volta Review 2005;105(2):129-150

2 Nikolopoulos TP, Lloyd H, Archbold S, O'Donoghue GM. Pediatric cochlear implantation: the parents' perspective. Arch Otolaryngol Head Neck Surg 2001;127(4):363-367

3 Kelsay DM, Tyler RS. Advantages and disadvantages expected and realized by pediatric cochlear implant recipients as reported by their parents. Am J Otol 1996;17(6): 866-873

4 Kluwin TN, Stewart DA. Cochlear implants for younger children: a preliminary description of the parental decision process and outcomes. Am Ann Deaf 2000;145(1):26-32

5 Archbold S, Harris M, O'Donoghue G, Nikolopoulos T, White A, Richmond HL. Reading abilities after cochlear implantation: the effect of age at implantation on outcomes at 5 and 7 years after implantation. Int J Pediatr Otorhinolaryngol 2008;72(10): 1471-1478

6 Beadle EA, Shores A, Wood EJ. Parental perceptions of the impact upon the family of cochlear implantation in children. Ann Otol Rhinol Laryngol Suppl 2000;185:111-114
7 Huttunen K, Välimaa T. Perceptions of parents and speech and language therapists on the effects of paediatric cochlear implantation and habilitation and education following it. Int J Lang Commun Disord 2012;47(2):184-196

8 Stefanini MR, Morettin M, Zabeu JS, Bevilacqua MC, Moret AL. Parental perspectives of children using cochlear implant. Codas 2014;26(6):487-493

9 Sach TH, Whynes DK. Paediatric cochlear implantation: the views of parents. Int J Audiol 2005;44(7):400-407

10 Weisel A, Most T, Michael R. Mothers' stress and expectations as a function of time since child's cochlear implantation. J Deaf Stud Deaf Educ 2007;12(1):55-64

11 Piazza E, Kandathil C, Carron JD. Parental expectations and outcomes of pediatric cochlear implantation. J Miss State Med Assoc 2009;50(10):331-336

12 Quittner AL, Steck JT, Rouiller RL. Cochlear implants in children: a study of parental stress and adjustment. Am J Otol 1991;12 (Suppl):95-104

13 Sarant J, Garrard P. Parenting stress in parents of children with cochlear implants: relationships among parent stress, child language, and unilateral versus bilateral implants. J Deaf Stud Deaf Educ 2014;19(1):85-106 